\title{
Metallurgical Analysis as a Useful Method for Fire Investigation: the Case of Galvanized Steel Sheets
}

\author{
A. Casaroli, M. Boniardi, R. Gerosa and B. Rivolta $\mathbb{D}^{*}$, Dipartimento Di \\ Meccanica, Politecnico Di Milano, Via La Masa 34, 20156 Milano, Italy
}

Received: 4 February 2021/Accepted: 10 July 2021/Published online: 3 August 2021

\begin{abstract}
In this work, fire simulations were carried out on zinc-coated steel sheets usually employed for the structural parts of furniture, transformer rooms and aeration pipes. The thermal alteration induced by the fire was simulated by heating samples at 13 different temperatures (from $20^{\circ} \mathrm{C}$ to $1050^{\circ} \mathrm{C}$ ) and for different exposure times $(1 \mathrm{~h}$ and $6 \mathrm{~h})$ in a laboratory furnace. The metallurgical investigation concerned the surface coloring by photographic analysis, the morphology and chemical composition of the surface oxides by SEM and EDS and the microstructure modifications as a function of the temperature by LOM. The influence of the different parameters was discussed by a statistical approach. The obtained results allowed to associate the temperature to one or more alteration of the steel microstructure and of the color, the morphology and the chemical composition of the surface oxides.
\end{abstract}

Keywords: Fire investigation, Metallographic analysis, Metals and alloys, Effective fire temperature

\section{Introduction}

The most common and employed standard related to fire investigations is the NFPA 921 (Guide for Fire and Explosion Investigations). Such document reports the visual analysis as one of the most important techniques to recreate the fire evolution. The path and the propagations of the flames may, sometimes, be identified studying the modifications produced by the heat on the objects present in the accident place [1].

After a fire, the investigation always focuses on three main aspects: (i) discover the fire origin, (ii) determine the fire cause and (iii) establish the responsibility for the fire $[2,3]$.

Usually, most of the information is obtained from the traces left by the flames (fire patterns) and by the depositions of the peoples.

The main consequences of the fire on the surrounding structures can be divided into two types: the movement patterns, that are related to the fire path and the intensity patterns related to the intensity of the flames [4].

\footnotetext{
*Correspondence should be addressed to: B. Rivolta, E-mail: barbara.rivolta@polimi.it
} 
Some examples of the movement patterns are the distance made by the flames on horizontal surfaces (floors or wood bases), the deformations of the light bulbs (pulled light bulbs) [5], the reduction of the mechanical properties of the mattress springs or the traces left by the heat reflected by objects that stop the fire movement (heat shadowing) [6].

In addition to this information, other proofs can be obtained by the marks left by the hot gases on the ceiling (e.g. concrete spalling) [7].

The most common examples of intensity patterns are instead the degree of carbonization of the wood surfaces [8], the calcination degree of the plasterboard walls and the fire plumes patterns [9] produced by the hot gases, by the flames and by the fumes. Generally, such evidences are truncated cone shaped and represent the boundaries of the flames, the hot gases and the fumes with the building walls.

Metal objects are very often found at the site of a fire, since they are generally not destroyed by the flames. For such objects, the NFPA 921 standard suggests the melting temperature as the only one parameter to estimate the fire temperature.

Apart of the aluminum alloys, the melting temperatures of the most common metals used in houses or in industrial plants (steels, stainless steels and copper alloys) are too high to be reached during a normal fire. Moreover, especially in case of legal controversy, strict and science-based evidences are required. This limit can be overcome by analyzing the characteristics and the modifications of the surface oxides and of the material microstructure. In fact, these features are characterized by transformations well correlated with the temperature and can be carefully observed by suitable microscopes [10], [11], [12]. Particularly, the microstructural modifications are stable and cannot be modified during the fire extinguishing [13], [14], [15]. Such metallurgical characteristics must be compared with reference data that are actually difficult to be found in the technical literature.

The present paper aims to remark the potentiality of the metallurgical analysis during a fire investigation [16-18]. Fire simulations were carried out on zinccoated steel sheets usually employed for the structural parts of furniture, transformer rooms and aeration pipes.

Such components are always present in houses or industrial buildings and are characterized by constant properties among the products available on the market.

\section{Materials and Methods}

Galvanized steel sheets were tested at different temperatures in a laboratory furnace to study their behaviour during a fire.

The whole experimental activity was developed aiming to duplicate the consequence of a fire in a partially confined space characterized by low humidity.

Such aim was obtained by mean of a laboratory muffle furnace with an oxidizing environment (air) with relative humidity of $50 \%$ at room temperature. The experimental activity didn't involve reducing atmosphere (e.g. hydrogen or carbon 
monoxide) characteristic of fires developed in a fully confined spaces where the oxygen amount is gradually consumed by the combustion process.

The air humidity was controlled carefully in order to prevent corrosion phenomena different from high temperature oxidation. It is important to remark that the environment features (oxidizing or reducing, with high or low humidity) can modify the surface oxides, but they cannot influence the steel (or any other metallic alloy) microstructure at all. It depends only on the fire temperature and duration.

The heat treatment was composed of three stages:

- fast increase of the temperature by putting the specimens in the hot furnace;

- soaking for 1 or $6 \mathrm{~h}$;

- air cooling.

After the heat treatment, each sample was subjected to the following analyses:

- visual analysis of the sheet surface color;

- SEM (Scanning Electron Microscope) observation and EDS (Energy-Dispersive X-ray Spectroscopy) analysis to study the morphology and the chemical composition of the surface oxides;

- metallographic analysis of the steel by LOM (Light Optical Microscope).

The average chemical composition of the steel is reported in Table 1.

The visual analysis was carried out by a digital reflex camera inside a suitable white room. The pictures were first modified by an ad-hoc calibration system in order to make the color independent of the used camera and to get the RGB channels histogram.

Such a procedure minimized the influence of the outer environment on the acquired image, so that the sheet color could be evaluated objectively.

After the visual analysis, the surface oxides morphology and chemical composition were investigated by SEM and EDS probe. Finally, the metallographic analysis revealed the structural modifications occurred in the steel.

The obtained results and observations can be associated to the heat developed by a fire and can be used to determine the temperature interval reached by a component made with zinc-coated sheets during the fire.

\section{Table 1}

Average Chemical Analysis of the Considered Steel After Mechanical Removal of the Zinc Coating

\begin{tabular}{lccccccr}
\hline $\mathrm{C}[\%]$ & $\mathrm{Mn}[\%]$ & $\mathrm{P}[\%]$ & $\mathrm{S}[\%]$ & $\mathrm{Si}[\%]$ & $\mathrm{Cr}[\%]$ & $\mathrm{Ni}[\%]$ & $\mathrm{Fe}[\%]$ \\
\hline 0.04 & 0.19 & 0.02 & 0.008 & 0.01 & 0.05 & 0.07 & 99.61 \\
\hline
\end{tabular}




\section{Visual and SEM Analysis}

Aiming to study the color assumed by a zinc-coated sheet after a fire, a completely random factorial plan with two repetitions per each experimental condition was selected.

Two main parameters were considered: (1) the fire temperature and (11) the heat exposure time.

The experimental plan involved 13 temperatures included among $20{ }^{\circ} \mathrm{C}$ and $1050{ }^{\circ} \mathrm{C}$. Such a maximum temperature is rarely exceeded during a fire.

The test temperatures $\left(20^{\circ} \mathrm{C}, 150{ }^{\circ} \mathrm{C}, 225^{\circ} \mathrm{C}, 300{ }^{\circ} \mathrm{C}, 340{ }^{\circ} \mathrm{C}, 375{ }^{\circ} \mathrm{C}, 415{ }^{\circ} \mathrm{C}\right.$, $450{ }^{\circ} \mathrm{C}, 525^{\circ} \mathrm{C}, 600{ }^{\circ} \mathrm{C}, 750{ }^{\circ} \mathrm{C}, 900{ }^{\circ} \mathrm{C}, 1050{ }^{\circ} \mathrm{C}$ ) were selected in the most critical intervals for the color variation.

The heat exposure time was fixed at $1 \mathrm{~h}$ and $6 \mathrm{~h}$ in order to study the material modifications after short- and long-lasting fires. The pictures were taken by a Canon EOS 450D digital reflex camera. The full experimental plan was hence composed of 26 conditions with two repetitions per each.

The specimens employed in the present investigation are $80 \mathrm{~mm}$ side squares obtained by blanking from a galvanized $0.6 \mathrm{~mm}$ thick steel sheet. The zinc coating thickness was included among $10 \mu \mathrm{m}$ and $15 \mu \mathrm{m}$. Before the furnace heating, the samples were cleaned carefully and after the soaking they were air cooled. Fast heating and cooling were considered in order to reproduce the actual conditions during a fire, especially in case of thin components.

All the pictures were taken on an optical bench equipped with four $150 \mathrm{~W}$ incandescence lamps (Fig. 1) and with a box able to diffuse the light. In order to keep the experimental condition as much constant as possible, the camera was fixed at $400 \mathrm{~mm}$ from the sheet and all the light sources different from the experimental set-up ones, were eliminated.

In order to minimize the influence of the used camera and of the lamps on the image color, a calibration procedure was employed to get the color as much similar as possible to the real one.

The pictures were saved in the camera RAW format and then the color was corrected using an ad-hoc calibration system.

The pictures were finally saved in the PNG format, using an 8-bit depth for each color channel. In this way, each color channel is represented by 256 values: 0 represents the black color and 255 the pure color. The RGB histograms and the related average values were calculated by a specific algorithm developed with the software Matlab ${ }^{\circledR}$ (Fig. 2).

The same surfaces were observed at $1000 \times$ by SEM Zeiss EVO 25. Semi-quantitative chemical analyses were carried out too by EDS probe.

\section{Metallographic Analysis}

From each sheet, two specimens were taken, one in the longitudinal and one in the transversal directions. All the samples were mirror polished according to the common metallographic technique by grinding papers up to 1200 grit and $3 \mu \mathrm{m}$ and $1 \mu \mathrm{m}$ diamond clothes. They were etched by Nital2 reagent $\left(\mathrm{HNO}_{3}, 2 \mathrm{ml}\right.$ and 


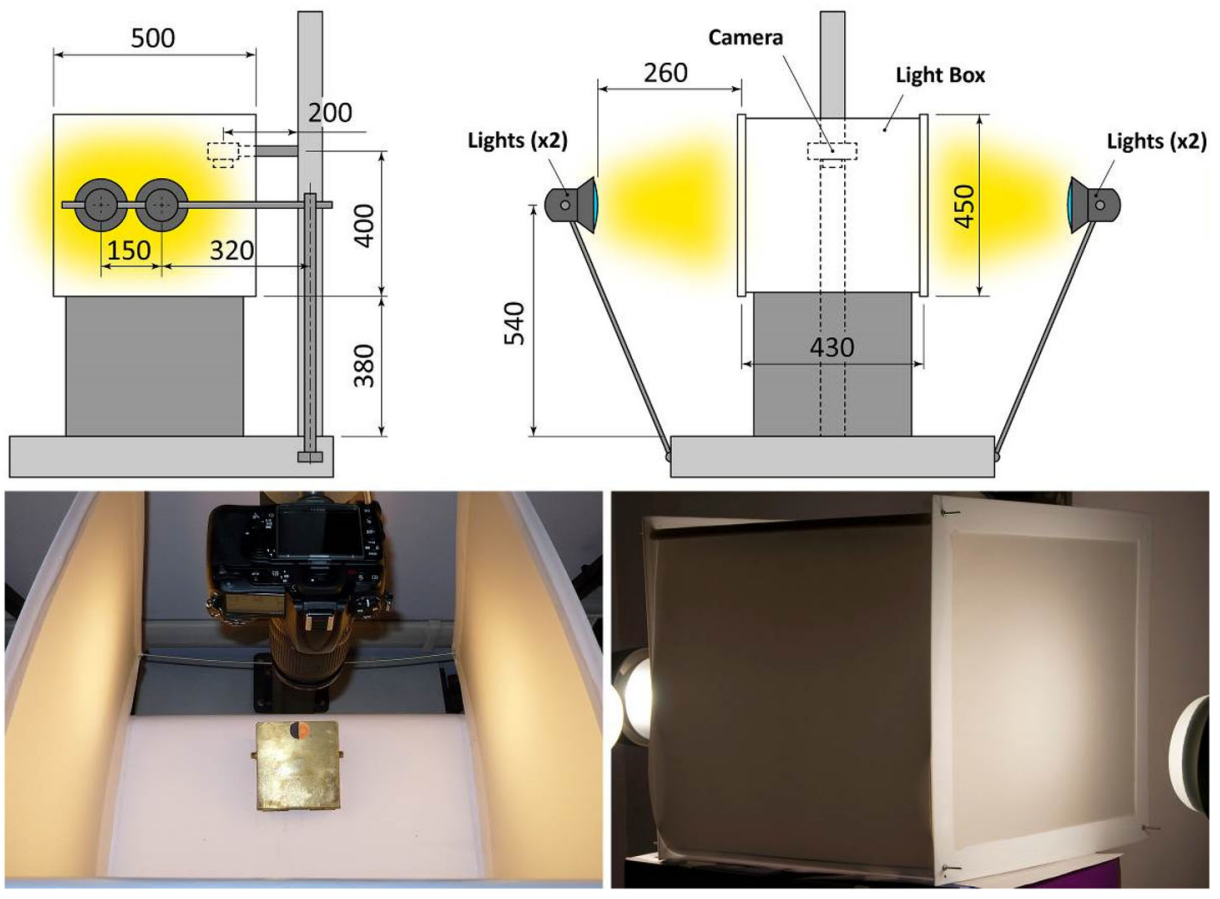

Fig. 1. Sketch of the photographic set-up employed in the described experimental investigation.

ethanol $98 \mathrm{ml}$ ). Finally, pictures at $500 \times$ were taken by LEICA ${ }^{\circledR}$ DM4000M optical microscope.

\section{Results and Discussion}

\subsection{Visual Analysis}

The visual analysis remarked that the temperature was the most important factor, whereas the exposure time seemed to be less influential.

The specimens exposed for $1 \mathrm{~h}$ at temperatures lower than $375^{\circ} \mathrm{C}$ showed no significant differences. In this interval the surfaces were smooth and showed a color made of light and dark grey zones. Also the reflective capacity showed no changes in respect to the $20^{\circ} \mathrm{C}$ specimen.

In the interval between $415^{\circ} \mathrm{C}$ and $450{ }^{\circ} \mathrm{C}$, some modifications of the zinc layer were visible becoming darker and opaque and with a rougher surface.

In the interval between $525^{\circ} \mathrm{C}$ and $600{ }^{\circ} \mathrm{C}$, the surface is characterized by a homogeneous and opaque dark grey color. The zinc coating was still adherent, but its roughness increased further.

At $750{ }^{\circ} \mathrm{C}$, the surface showed small black colored iron oxide stains. The oxide layer is crumbly and can be removed easily. 

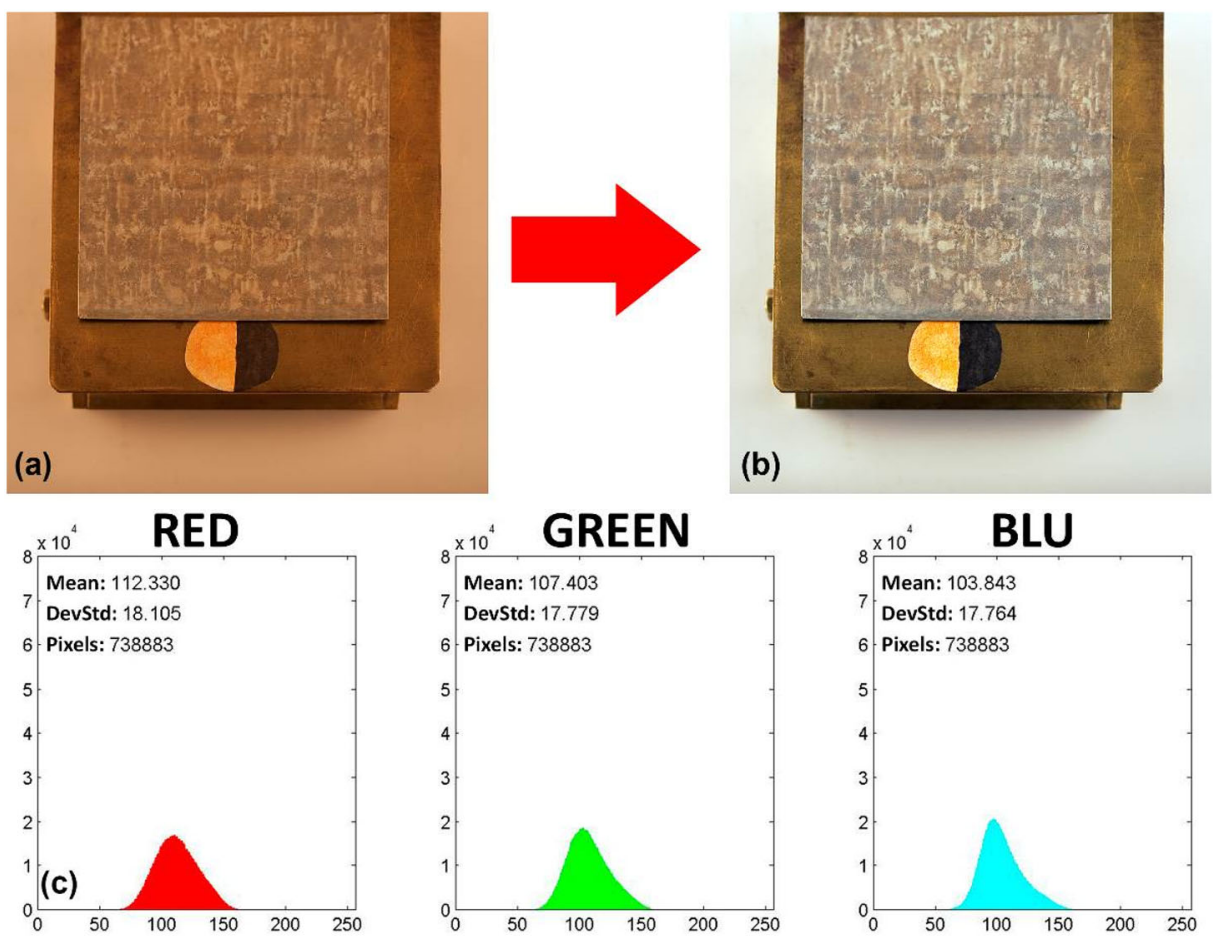

\section{Fig. 2. Original image (a) and after the color calibration (b)-(c) RCB histograms calculated by the Matlab ${ }^{\circledR}$ algorithm.}

At $900{ }^{\circ} \mathrm{C}$ the iron oxide stain diameter increased up to $20 \mathrm{~mm}$ and $30 \mathrm{~mm}$. The zinc layer is completely oxidized and it is characterized by a dark yellow color. Both the iron and the zinc oxides are crumbly and can be removed easily.

At $1050{ }^{\circ} \mathrm{C}$ the specimens are deformed and covered by a thick iron oxide layer that broke off the surface. The zinc coating was no more visible.

The specimens tested for $6 \mathrm{~h}$ showed the same features of the $1 \mathrm{~h}$ tested material, even if they appeared at about $100{ }^{\circ} \mathrm{C}$ less in respect to the $1 \mathrm{~h}$ soaking samples.

Figures 3 and 4 show some of the specimens heated at the planned temperatures and times. RGB average and standard deviation data are reported, together with the corresponding image.

\section{SEM Analysis}

As reported in Fig. 5, the SEM observations on the $20^{\circ} \mathrm{C}$ specimen showed a dendritic morphology of the zinc coating. The backscattered electron and the EDS analyses remarked a certain amount of aluminum (the darker zones) inside the zinc matrix (the lighter zones). 

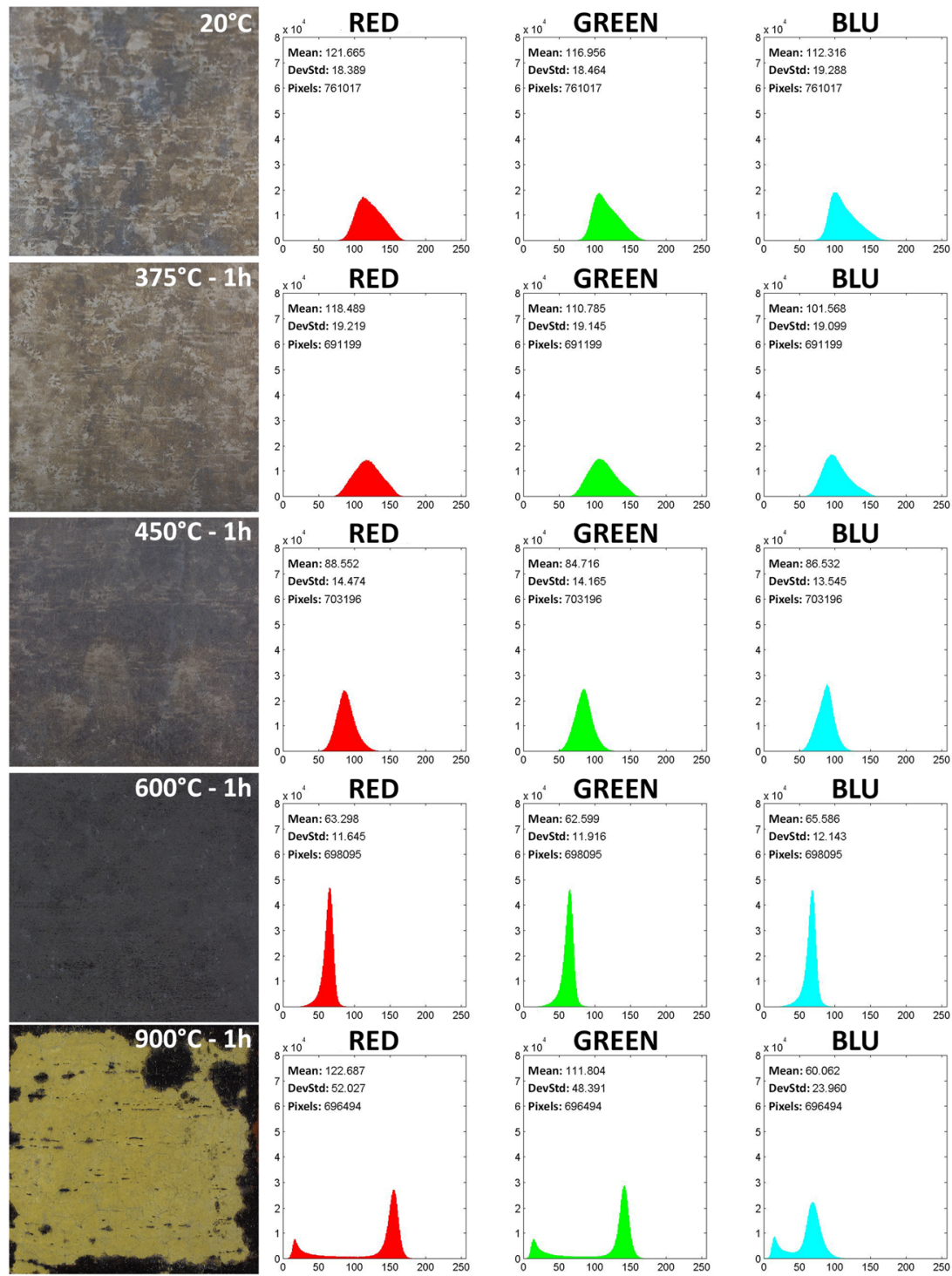

$1050^{\circ} \mathrm{C}-1 \mathrm{~h}$
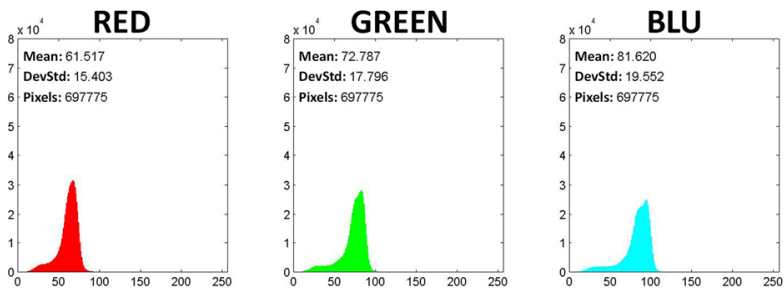

Fig. 3. Specimens heated for $1 \mathrm{~h}$ at $20^{\circ} \mathrm{C}, 375{ }^{\circ} \mathrm{C}, 450{ }^{\circ} \mathrm{C}, 600^{\circ} \mathrm{C}$, $750^{\circ} \mathrm{C}, 900^{\circ} \mathrm{C}$ and $10500^{\circ} \mathrm{C}$. 

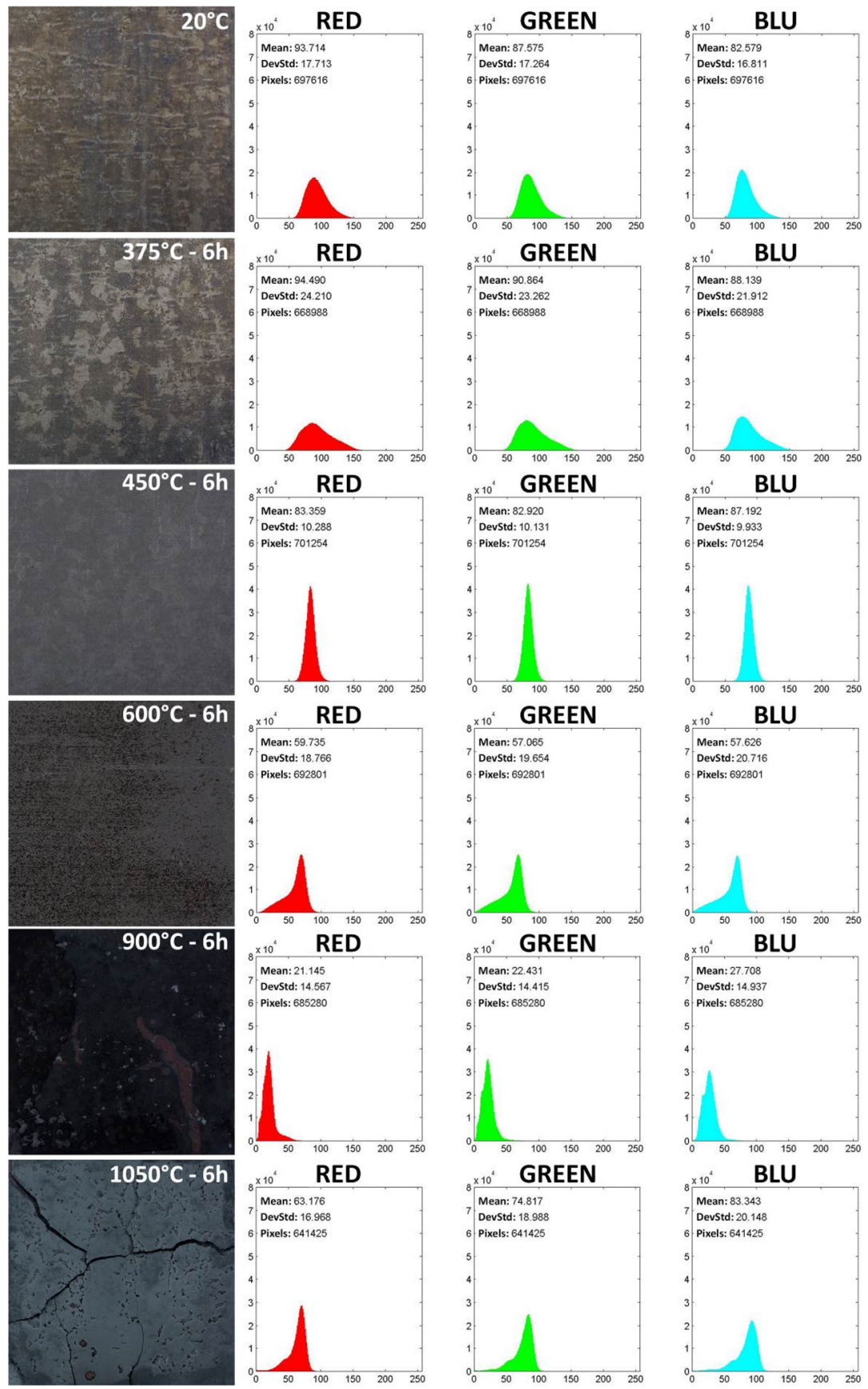

Fig. 4. Specimens heated for $6 \mathrm{~h}$ at $20^{\circ} \mathrm{C}, 375{ }^{\circ} \mathrm{C}, 450{ }^{\circ} \mathrm{C}, 600^{\circ} \mathrm{C}$, $750{ }^{\circ} \mathrm{C}, 900^{\circ} \mathrm{C}$ and $1050{ }^{\circ} \mathrm{C}$. 


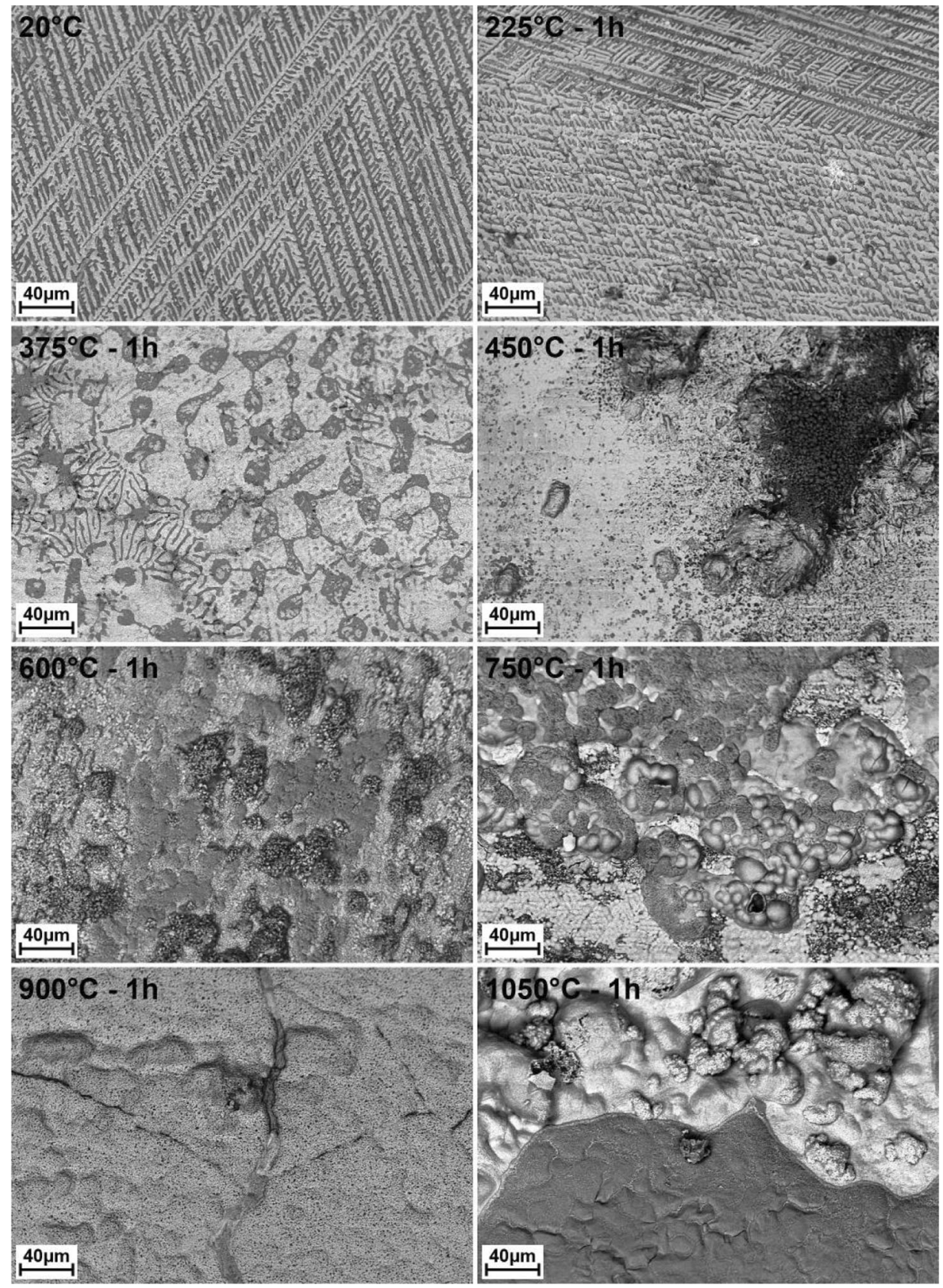

Fig. 5. Surface oxide morphology of the sheets heated for $1 \mathrm{~h}$ at $20^{\circ} \mathrm{C}, 225{ }^{\circ} \mathrm{C}, 375{ }^{\circ} \mathrm{C}, 450^{\circ} \mathrm{C}, 600^{\circ} \mathrm{C}, 750^{\circ} \mathrm{C}, 900^{\circ} \mathrm{C}$ and $1050{ }^{\circ} \mathrm{C}$. SEM analysis (Magnification: $1000 x$ ). 
At $375{ }^{\circ} \mathrm{C}$, the zinc is subjected to the first melting phenomena that modify both the shape and the dimensions of the zinc-rich grains, because they start to expand on the sheet surface.

Melting became more and more evident at $415-450{ }^{\circ} \mathrm{C}$, temperature at which the dendritic shape of the grains is no more visible, being the new grains geometry more rounded. The first traces of iron oxide appeared.

Between $525^{\circ} \mathrm{C}$ and $600{ }^{\circ} \mathrm{C}$, zinc, iron and aluminum oxides were present. Their larger volume justifies the increase of surface roughness. At $750{ }^{\circ} \mathrm{C}$, the amount of iron oxide increased quickly and between $900^{\circ} \mathrm{C}$ and $1050^{\circ} \mathrm{C}$ the oxide layer chipped easily.

Figure 6 shows the EDS analysis performed on the tested specimens: the oxygen and iron contents increase starting from $415^{\circ} \mathrm{C}$; on the other hand, the percentage of zinc and aluminum decreases until $900^{\circ} \mathrm{C}-1050{ }^{\circ} \mathrm{C}$ where it is almost zero.

The $6 \mathrm{~h}$ treated specimens showed a similar behavior even if the abnormal iron oxide growth started at lower temperature (about $600{ }^{\circ} \mathrm{C}$ ) in respect to the $1 \mathrm{~h}$ soaking. The SEM surface observation and the chemical composition are reported in Figs. 7, 8 respectively.

\section{Metallographic Analysis}

The metallographic analysis made on the specimens in the original conditions, revealed a mainly ferritic microstructure, with small percentages of pearlite; the grains appeared strongly elongated along the rolling direction. In the transversal section, the average grain size was about $15 \mu \mathrm{m}$. Such microstructure appeared unchanged up to $450{ }^{\circ} \mathrm{C}$ for both $1 \mathrm{~h}$ and $6 \mathrm{~h}$ soaking. From $525^{\circ} \mathrm{C}$, recovery and recrystallization occurred [19], [20]. The final average grain size was about $15 \mu \mathrm{m}$.

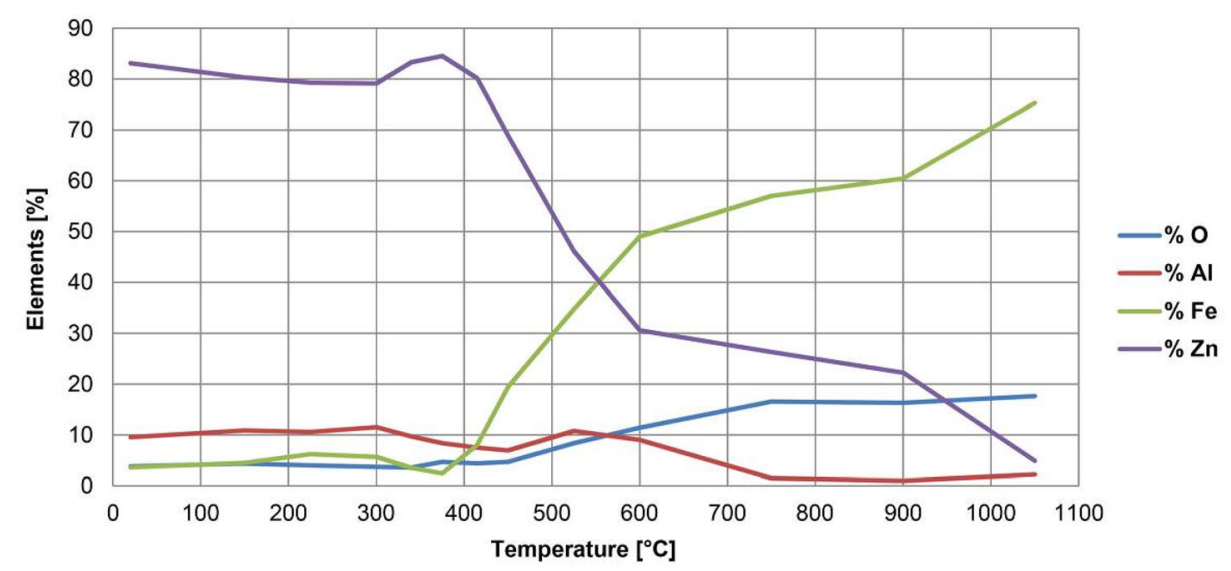

Fig. 6. Chemical composition of the sheet specimens heated for 1 h-EDS analysis. 


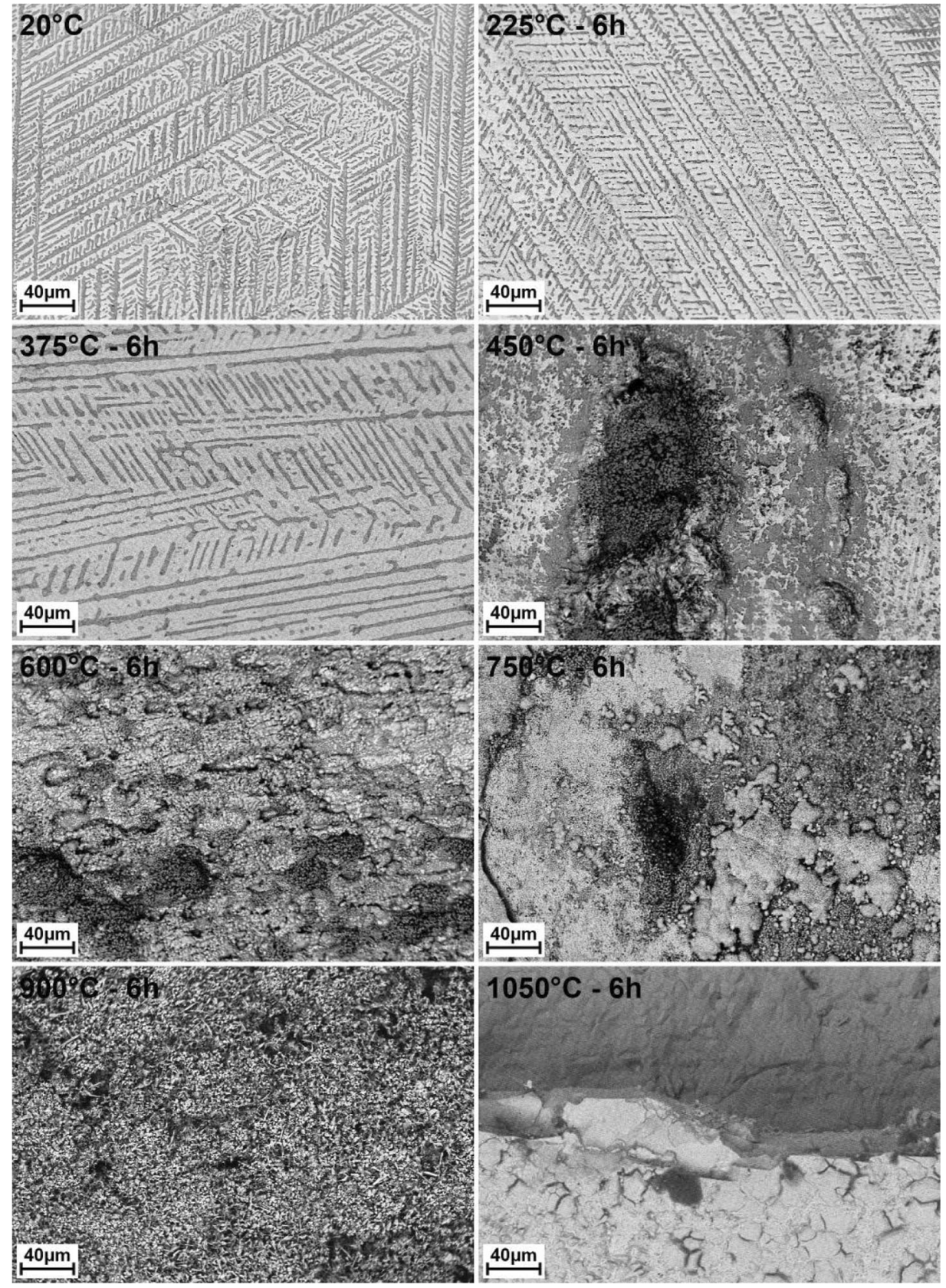

Fig. 7. Surface oxide morphology of the sheets heated for $6 \mathrm{~h}$ at $20^{\circ} \mathrm{C}, 225{ }^{\circ} \mathrm{C}, 375{ }^{\circ} \mathrm{C}, 450^{\circ} \mathrm{C}, 600^{\circ} \mathrm{C}, 750^{\circ} \mathrm{C}, 900^{\circ} \mathrm{C}$ and $1050{ }^{\circ} \mathrm{C}$. SEM analysis (Magnification: $1000 x$ ). 


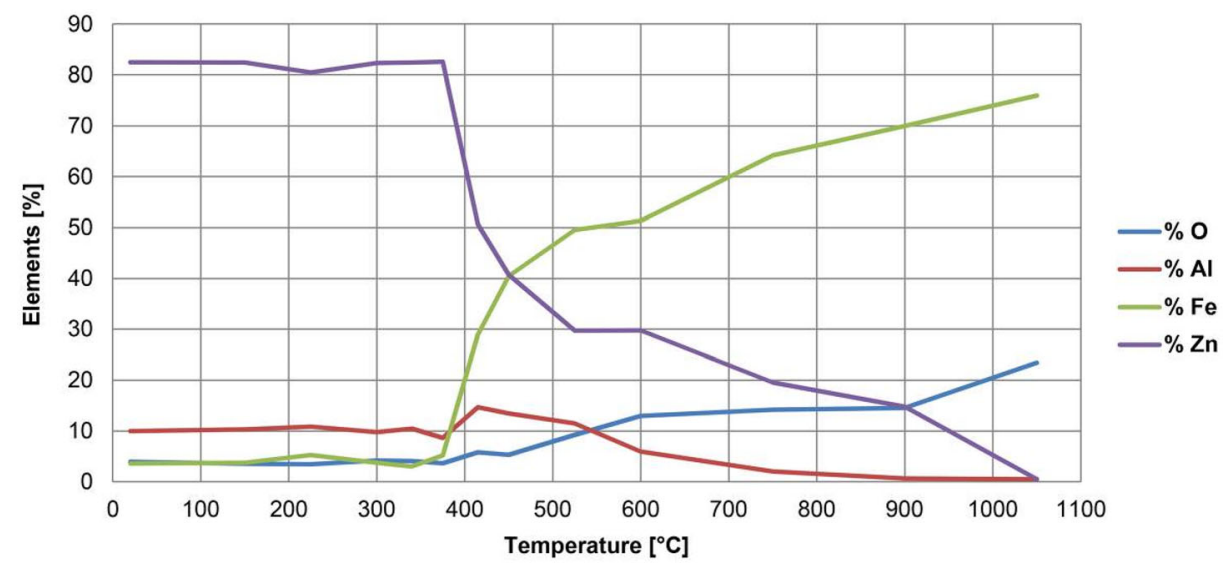

Fig. 8. Chemical composition of the sheet specimens heated for $6 \mathrm{~h}$-EDS analysis.

At $750{ }^{\circ} \mathrm{C}$, a $10 \mu \mathrm{m}-15 \mu \mathrm{m}$ thick iron oxide layer was created. The microstructure was made of polygonal equiaxial grains with an average dimension of $30 \mu \mathrm{m}$. The grain coarsening was enhanced by the high temperature and by the long soaking times. Moreover, decarburization occurred, as confirmed by the absence of pearlite. From $900^{\circ} \mathrm{C}$ and $1050{ }^{\circ} \mathrm{C}$, both the grain coarsening and the development of iron oxide accelerated strongly. The average grain sizes were equal to $60 \mu \mathrm{m}$ and $90 \mu \mathrm{m}$ for the soaking at $900{ }^{\circ} \mathrm{C}$ and $1050{ }^{\circ} \mathrm{C}$ respectively. The oxide layer detached easily and the sheet thickness decreased down to $0.1-0.3 \mathrm{~mm}$, as reported in Fig. 9.

As expected, the specimens treated for $6 \mathrm{~h}$ showed similar features, but the grain coarsening and the oxide growth were much larger. Figures 10 and 11 show the described microstructural investigation.
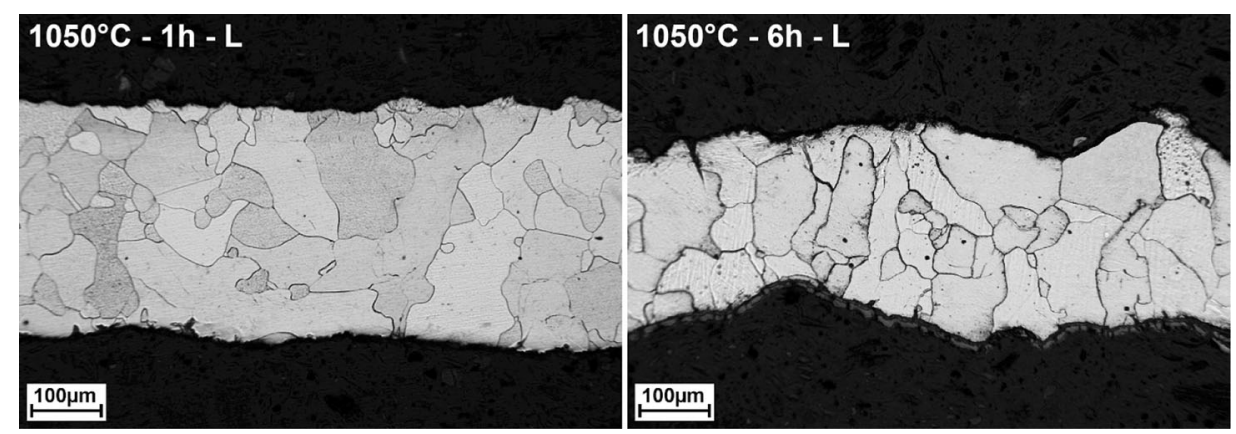

Fig. 9. Microstructural features of two specimens heated at $10500^{\circ} \mathrm{C}$ for $1 \mathrm{~h}$ and $6 \mathrm{~h}$ (Longitudinal "L"' direction, magnification: 100x, reagent: Nital2). 


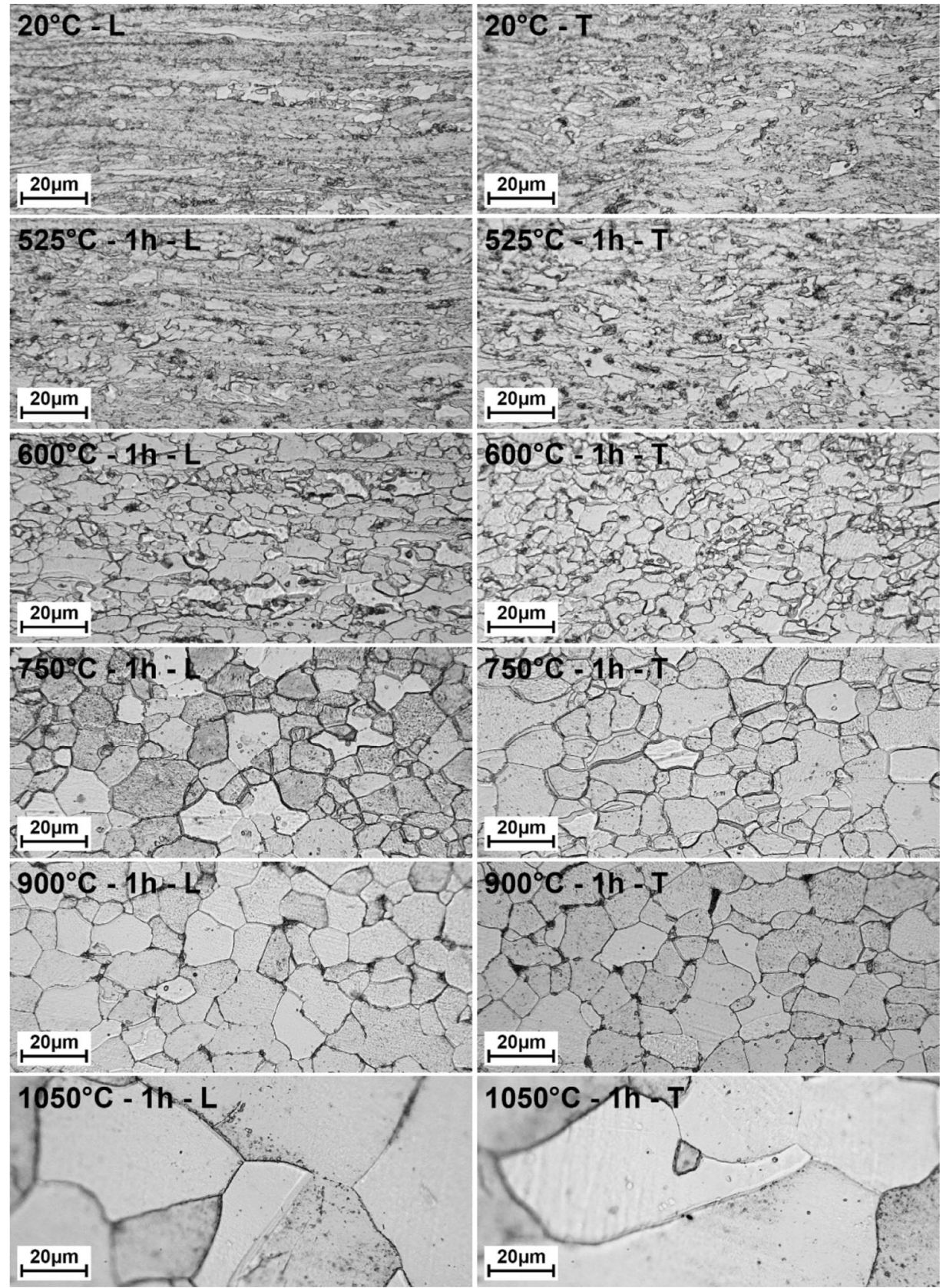

Fig. 10. Microstructural analysis of the sheets heated for $1 \mathrm{~h}$ at $20^{\circ} \mathrm{C}, 525^{\circ} \mathrm{C}, 600^{\circ} \mathrm{C}, 750^{\circ} \mathrm{C}, 900^{\circ} \mathrm{C}$ and $1050^{\circ} \mathrm{C}$ in the longifudinal (L) and transversal (T) directions (Magnification: 500x, reagent: Nital2). 

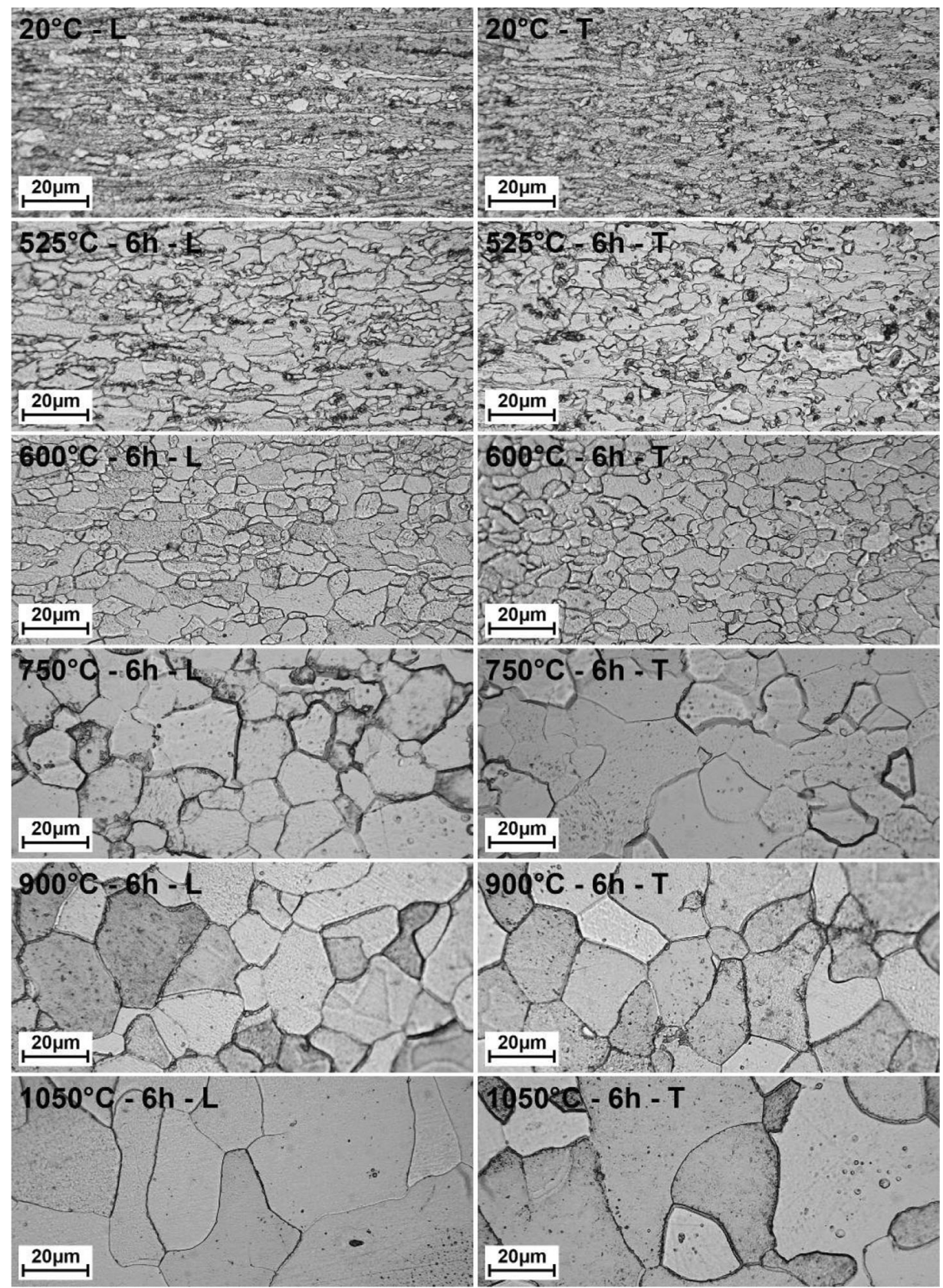

Fig. 11. Microstructural analysis of the sheets heated for $6 \mathrm{~h}$ at $20^{\circ} \mathrm{C}, 525^{\circ} \mathrm{C}, 600^{\circ} \mathrm{C}, 750{ }^{\circ} \mathrm{C}, 900^{\circ} \mathrm{C}$ and $1050^{\circ} \mathrm{C}$ in the longifudinal (L) and transversal (T) directions (Magnification: 500x, reagent: Nital2). 


\section{Conclusions}

In the present experimental work, fire simulations were carried out on zinc-coated steel sheets usually employed in the structural parts of furniture, transformer rooms and aeration pipes.

The $80 \mathrm{~mm} \times 80 \mathrm{~mm}$ specimens were taken from a galvanized cold rolled $0.6 \mathrm{~mm}$ thick carbon steel sheet. The specimens were heated at different temperatures between $20^{\circ} \mathrm{C}$ and $1050{ }^{\circ} \mathrm{C}$ for 1 and $6 \mathrm{~h}$. Three main investigations were performed in order to associate each temperature to the surface visual and chemical properties and to the microstructural variations:

- the surface color;

- the morphology and the chemical composition of the zinc layer and of the generated oxides;

- the microstructural characterization as function of the test temperature.

About the color analysis, it was proved that both the temperature and the exposure time influence the color and the thickness of the surface oxides: in respect to the $1 \mathrm{~h}$ treatments, after $6 \mathrm{~h}$ soaking, thicker oxides and a darker color were observed on the samples surfaces.

The visual analysis showed that among $20{ }^{\circ} \mathrm{C}$ and $375^{\circ} \mathrm{C}$, the surface color showed no changes significantly. In the temperature interval $415{ }^{\circ} \mathrm{C}-450{ }^{\circ} \mathrm{C}$, the zinc layer became darker and opaque and its roughness increased. From $525{ }^{\circ} \mathrm{C}$ to $600{ }^{\circ} \mathrm{C}$, the surface color was uniformly opaque and dark gray. The presence of the iron oxide was evident starting from $750{ }^{\circ} \mathrm{C}$ and it enlarged as the temperature increased. At $900{ }^{\circ} \mathrm{C}$ the amount of the zinc layer was strongly reduced and assumed a yellow color. At $1050{ }^{\circ} \mathrm{C}$, it disappeared completely.

The SEM observations revealed the dendritic morphology of the zinc layer at $20{ }^{\circ} \mathrm{C}$. Such morphology changed starting from $375{ }^{\circ} \mathrm{C}$ and disappeared at $450{ }^{\circ} \mathrm{C}$. Among $525^{\circ} \mathrm{C}$ and $600^{\circ}$, zinc, aluminum and iron oxides appeared, but after $750{ }^{\circ} \mathrm{C}$, only the iron oxide was present with many chips created by its fracture.

In the temperature interval $20{ }^{\circ} \mathrm{C}-450{ }^{\circ} \mathrm{C}$, the microstructural analysis revealed the presence of ferrite and small percentages of pearlite, both elongated along the rolling direction. At $525{ }^{\circ} \mathrm{C}$ recovery and recrystallization started and the grain dimension became polygonal and equiaxial. The average size was about $15 \mu \mathrm{m}$. At $750{ }^{\circ} \mathrm{C}$, three metallurgical phenomena were activated: (1) grain growth, (11) strong surface oxidation and (111) steel decarburization.

Their intensity grew as the temperature increased, leading to large grain size, strong reduction of the sheet thickness and the pearlite disappearance.

Such metallurgical phenomena, together with the surface color, can finally be considered basic tools to determine the fire temperature carefully.

These results can be summarized in a table that highlights the most important morphological and microstructural alterations by correlating to a given time and temperature (Fig. 12). 


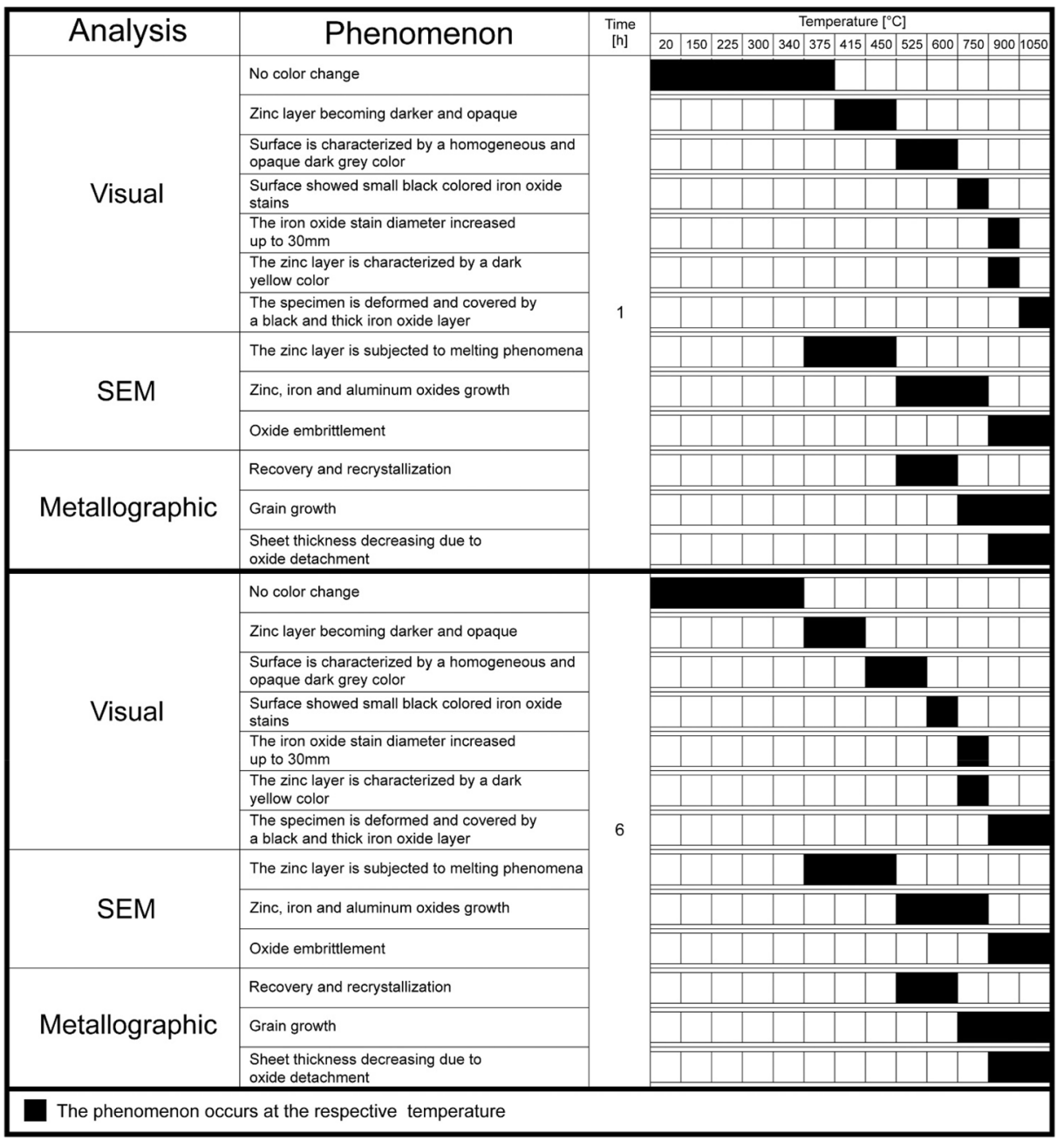

\section{Fig. 12. Correlation between time, temperature and modifications observed on zinc-coated steel sheets.}

Consequently, the discovery of zinc-coated steel sheets at the site of a fire (e.g. structural parts of furniture, transformer rooms and aeration pipes) could be of help in determining the temperature range reached during the fire.

However, it is important to remember that all tested specimens have: (i) reduced thickness, (ii) homogeneous temperature throughout the thickness and (iii) have been air-cooled. For these reasons it is important to rely on expert judgment in addition to referring to Fig. 12.

Funding Open access funding provided by Politecnico di Milano within the CRUI-CARE Agreement. 


\section{Open Access}

This article is licensed under a Creative Commons Attribution 4.0 International License, which permits use, sharing, adaptation, distribution and reproduction in any medium or format, as long as you give appropriate credit to the original author(s) and the source, provide a link to the Creative Commons licence, and indicate if changes were made. The images or other third party material in this article are included in the article's Creative Commons licence, unless indicated otherwise in a credit line to the material. If material is not included in the article's Creative Commons licence and your intended use is not permitted by statutory regulation or exceeds the permitted use, you will need to obtain permission directly from the copyright holder. To view a copy of this licence, visit http://creat ivecommons.org/licenses/by $/ 4.0 /$.

\section{References}

1. NFPA 921: Guide for Fire and Explosion Investigations, National Fire Protection Association (NFPA), Quincy, Massachusetts, 2008

2. C. Ortolani, Casi di combustioni accidentali - Volumi 1 e 2, Maggioli Editori, Sant'Arcangelo di Romagna, Italia, 2007

3. D.J. Icove, Kirk's Fire Investigation $8^{\text {th }}$ edition, Pearson Education, London, United Kingdom, 2017

4. Lentini JJ (2006) Scientific protocols for fire investigation. CRC Press - Taylor \& Francis Group, Boca Raton, Florida

5. A. De Rosa, L. Bottà, A. Fiorillo, La semiotica degli incendi, Nucleo Investigativo Antincendi del Corpo Nazionale Vigili del Fuoco, Roma, Italia, 2015

6. Almirall JR, Furton KG (2004) Analysis and interpretation of fire scene evidence. CRC Press - Taylor \& Francis Group, Boca Raton, Florida

7. Stauffer E, Dolan JA, Newman R (2008) Fire debris analysis. Academic Press - Elsevier, San Diego, California

8. Babrauskas V (2005) Charring rate of wood as a tool for fire investigations. Fire Saf $\mathbf{J}$ 40:528-554

9. D.J. Icove, J.D. DeHaan, "Hourglass" burn patterns: a scientific explanation for their formation, International Symposium On Fire Investigation Science and Technology, National Association of Fire Investigators, 2006

10. ASM Handbook, Volume 2, Properties and Selection: Nonferrous Alloys and SpecialPurpose Materials, ASM International, Materials Park, Ohio, 2004

11. ASM Handbook, Volume 9, Metallography and microstructure, ASM International, Materials Park, Ohio, 2004

12. Callister WD (2000) Material science and engineering: an introduction, 5th edn. Wiley, New York

13. Levinson DW (1977) Copper metallurgy as a diagnostic tool for analysis of the origin of building fires. Fire Technol 13:211-222

14. Chi JH, Peng PC (2017) Using the microstructure and mechanical behavior of steel materials to develop a new fire investigation technology. Fire And Mater 41(7):864-870 
15. Xie D, Shan G, Lv S (2018) Oxidation behavior of carbon steel in simulated kerosene combustion atmosphere: a valuable tool for fire investigations. Fire And Materials 42(2):156-163

16. Boniardi M, Casaroli A (2015) In-depth approach to fire investigations: microstructural analysis of metallic materials. Fire Mater 39:600-618

17. Boniardi M, Casaroli A (2014) Metallurgical modification as a tool for fire invetigations. Appl Fire Sci 23(4):467-493

18. Boniardi M, Casaroli A (2014) Influence of heat on non-ferrous objects: metallurgical analysis in fire scene investigations. Fire Technol 50:1335-1356

19. D. Raabe, 23 - Recovery and Recrystallization: Phenomena, Physics, Models, Simulation, Physical Metallurgy (Fifth Edition), (2014) 2291-2397

20. Torres CER, Sánchez FH, González A, Actis F, Herrera R (2002) Study of the kinetics of the recrystallization of cold-rolled low-carbon steel. Metall and Mater Trans A $33: 25-31$ 